\title{
Human pharmacokinetics of marcellomycin
}

\author{
P. Dodion ${ }^{3}$, M. Rozencweig ${ }^{2}$ C. Nicaise ${ }^{2}$, M. Watthieu ${ }^{2}$, J. M. Tamburini', \\ C. E. Riggs, jr. ${ }^{2}$, and N. R. Bachur ${ }^{3}$ \\ 1 University of Maryland Cancer Center, Division of Developmental Therapeutics, 22 South Green Street, Baltimore, MD 21201, USA \\ ${ }^{2}$ Institut Jules Bordet, Brussels, B-1000 Belgium, \\ ${ }^{3}$ Laboratory of Medicinal Chemistry and Biology, National Cancer Institute, DCT, NIH, Bethesda, MD 20205, USA
}

Summary. In conjunction with two phase I clinical trials, we have investigated the pharmacokinetics of marcellomycin (MCM), a new class II anthracycline antibiotic, in nine patients with normal renal and hepatic functions and no third-space fluid accumulation. MCM was infused $I V$ over $15 \mathrm{~min}$ at a dosage of $27.5,40$, or $50 \mathrm{mg} / \mathrm{m}^{2}$. Plasma and urine samples were collected up to 72 h. MCM and metabolites were assayed by thin-layer chromatography and quantified by specific fluorescence. The disappearance of total MCM-derived fluorescence from plasma followed first-order kinetics and lacked the rebound in total fluorescence that has been described for the structurally similar agent, aclacinomycin A. After $40-50 \mathrm{mg} / \mathrm{m}^{2}$, the peak $M C M$ concentration in plasma was $1.67 \pm 0.61 \mu M ; M C M$ disappeared from plasma in a triexponential fashion and was undetectabel by $48 \mathrm{~h}$ after infusion. The area under the plasma concentration-time plot ( $A U C$ ), including the infusion time, was $1.11 \pm 0.39 \mu M \times h$; plasma clearance of MCM was $1.50 \pm$ $0.88 \mathrm{l} / \mathrm{min} / \mathrm{m}^{2}$. Five other fluorescent compounds were consistently observed in plasma. $M 2$ was a contaminant present in the parent drug. $P 1$ and $P 2$ were conjugates of $M C M$ and $M 2$, respectively. $G 1$ and $G 2$ were aglycones. The peak concentrations of the metabolites were $25 \%$ or less or the peak concentration for $M C M$, but their persistence resulted in higher AUCs than that for MCM. For the dosage of $27.5 \mathrm{mg} / \mathrm{m}^{2}$, fewer data were available; but the pharmacokinetics of MCM and metabolites appeared to be similar to that at higher dosage. Urinary excretion of total fluorescence amounted to $8.0 \% \pm$ $1.6 \%$ of the total dose at $40-50 \mathrm{mg} / \mathrm{m}^{2}$, and to $7.0 \% \pm 2.3 \%$ at $27.5 \mathrm{mg} / \mathrm{m}^{2}$. No correlation was detected among the various pharmacokinetic parameters and toxicities encountered in these patients.

\section{Introduction}

Anthracycline antibiotics are a major class of antitumor agents. Two anthracyclines, Adriamycin (ADM) and daunorubicin (DNR), have been used extensively to treat a wide variety of solid and hematologic malignancies in humans. However, their administration may be complicated by the occurrence of serious and sometimes life-threatening side-effects. One of the most serious side-effects of the anthracycline

Offprint requests to: $\mathrm{N}$. R. Bachur

This work was presented in part at the Annual Meeting of the American Society of Clinical Oncology, San Diego, CA, May 1983 antibiotics is a cardiomyopathy associated with progressive and often irreversible heart failure. The risk of developing ADM-induced cardiomyopathy increases with rising cumulative doses of drug. Therefore, there have been continuous efforts to develop new naturally occurring or semisynthetic anthracyclines with a better therapeutic index.

Marcellomycin (MCM) (Fig. 1) is a new anthracycline antibiotic obtained from fermentation broth of an Actinosporangium species [14] and is the second class II anthracycline introduced into clinical trials. Structurally, MCM, like aclacinomycin A (ACL), has a trisaccharide linked to carbon 7 , whereas ADM and DNR contain only one sugar at this position. Trisaccharidic anthracyclines belong to the group of class II anthracyclines which inhibit nucleolar RNA synthesis at concentrations 100 - to 1,000 -fold lower than those required to inhibit DNA synthesis, in contrast to class I anthracyclines, including ADM and DNR, which inhibit nucleolar RNA and DNA syntheses at similar concentrations $[6,16,18]$.

Experimental observations suggesting that MCM possessed a reduced myelosuppressive potential made MCM attractive for clinical trials. Preclinical toxicologic investigations showed that, at lethal or sublethal doses, MCM induced little myelosuppression in mice and dogs $[4,18]$, and in vitro studies demonstrated MCM to be two to three times less toxic than ACL to human myeloid bone marrow stem cells [20]. In addition, the cardiotoxicity of MCM in rats and mice appeared to be less than that induced by ADM [18].

However, in the two clinical trials conducted so far, myelosuppression was the major and dose-limiting toxicity of MCM $[13,15]$. In addition, the myelotoxicity of MCM was
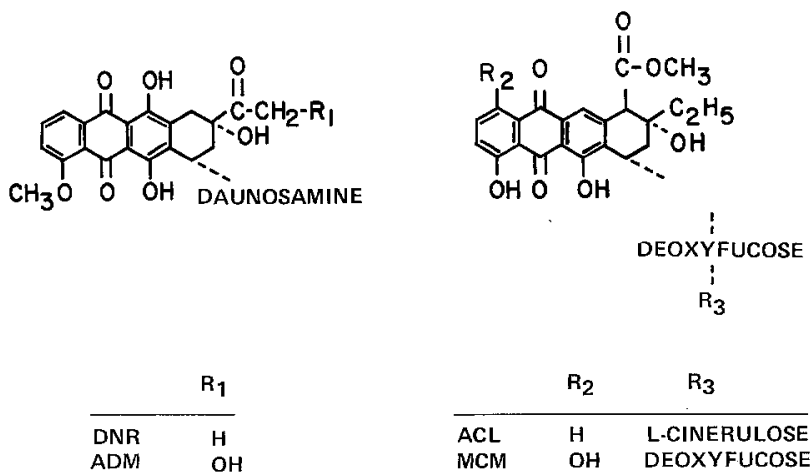

Fig. 1. Structure of marcellomycin, aclacinomycin A, Adriamycin, and daunorubicin 
erratic and unpredictable, both among individual patients and for repeated courses in a given patient.

Since variations in drug metabolism and disposition between laboratory animals and humans, and among patients, might account for the observed differences in toxicology, we initiated an extensive pharmacologic evaluation of MCM. The present study describes the metabolism and pharmacokinetics of this new anthracycline in man. Its pharmacokinetic behavior in mice has been described previously [7].

\section{Materials and methods}

Drug supply and purity. MCM was kindly supplied by Bristol-Myers Laboratories, Syracuse, NY. Drug purity was studied by thin-layer chromatography (TLC). We used silica gel 60 plates that were developed in an ascending fashion with one of the following systems: chloroform/methanol/acetic acid/water, $80: 20: 14: 6(\mathrm{v} / \mathrm{v} / \mathrm{v} / \mathrm{v})$ (system I); and chloroform/methanol/acetic acid, $100: 2: 2.5(\mathrm{v} / \mathrm{v} / \mathrm{v})$ (system II). The drug contained $90 \%$ MCM. The major contaminants were a slightly more polar compound (M2) and an aglycone, bisanhydropyrromycinone, representing $2.8 \%$ and $4.3 \%$ of the fluorescence, respectively. Three other minor compounds accounted for $2.9 \%$ of fluorescence. The composition of the drug was fairly similar from one batch to another. For example, the percentage of MCM ranged from $87.9 \%$ to $9.19 \%$ in six determinations.

Chemicals and reagents. Silica gel 60 plates $(250 \mu \mathrm{m})$ were obtained from E. Merck, Darmstadt, Germany. $\beta$-glucuronidase (type B1, from bovine liver), arylsulfatase (type 5, from limpets), phenolphthalein glucuronic acid, $p$-nitrocatechol sulfate, glucose-6-phosphate, $\mathrm{NADP}^{+}$, and glucose-6-phosphate dehydrogenase were obtained from Sigma Chemicals, St. Louis, Mo. All other reagents were reagent grade.

Patients and sample collections. Pharmacokinetic parameters were determined in nine cancer patients, six men and three women, aged 30-68 years (median: 58 years) who were entered in two phase- 1 trials $[13,15]$. All had advanced disease not amenable to control by surgery, radiation therapy, hormonal therapy, or conventional chemotherapeutic agents. All patients gave informed consent before being studied.

All patients but one were investigated during their first course of therapy with MCM. The drug was administered as an IV infusion over $15 \mathrm{~min}$ at dosages of $27.5,40$, or $50 \mathrm{mg} / \mathrm{m}^{2}$. Blood was collected in heparinized tubes and was immediately centrifuged at $12,000 \mathrm{~g}$ for $2 \mathrm{~min}$. The resulting plasma was frozen immediately and stored at $-20^{\circ} \mathrm{C}$ until analyzed. Urines were collected, frozen, and stored at $-20^{\circ} \mathrm{C}$ until analyzed.

Plasma analysis. Plasma samples were analyzed according to a modification of the method described by Benjamin et al. [3]. Standards were prepared by the addition of known amounts of MCM to $1 \mathrm{ml} 0.154 M$ sodium chloride. For the assay of total fluorescence, $1 \mathrm{ml}$ plasma or a standard was extracted with $2 \mathrm{ml}$ isopropanol $/ 2.16 N$ sulfuric acid, $75: 25(\mathrm{v} / \mathrm{v})$. The extracts were stored overnight at $4^{\circ} \mathrm{C}$ and centrifuged for $15 \mathrm{~min}$ at $47,500 \mathrm{~g}$ at $4^{\circ} \mathrm{C}$. The fluorescence of the resulting supernatant was measured. All fluorescence determinations were done on an Aminco-Bowman spectrofluorometer (SLM Instruments Inc., Urbana, Ill) at an excitation wavelength of $470 \mathrm{~nm}$ and an emission wavelength of $550 \mathrm{~nm}$. Fluorescence values were corrected for nonspecific endogenous fluorescence as determined from plasma sampled prior to treatment with MCM.

For the quantification of parent drug and metabolites, $1 \mathrm{ml}$ plasma was extracted with $2 \mathrm{ml}$ chloroform/isopropanol, $1: 1$ $(v / v)$. The organic phase was separated by centrifugation at $27,000 \mathrm{~g}$ for $15 \mathrm{~min}$, collected, and dried under a nitrogen jet. The dried residue was redissolved in $100 \mu \mathrm{l}$ chloroform $/ \mathrm{me}$ thanol, $1: 1(\mathrm{v} / \mathrm{v})$, and $40-\mu$ l portions were spotted on a TLC plate. All TLC plates were routinely spotted with standards consisting of MCM, musettamycin, pyrromycin, pyrromycinone, 7-deoxypyrromycinone, and bisanhydropyrromycinone (Fig. 2). Plates were developed in an ascending fashion in ethylacetate for $18 \mathrm{~cm}$, air-dried, and developed in an ascending fashion for $14 \mathrm{~cm}$ in system I. Occasionally, when a better separation of the aglycones was desired, the plates were developed immediately in system II for $16 \mathrm{~cm}$. Fluorescent spots were identified under a 254-nm UV light (UVS Mineralight, Ultraviolet Product, San Gabriel, Calif), scraped, eluted into $2 \mathrm{ml}$ isopropanol/2.16 N sulfuric acid, $75: 25(\mathrm{v} / \mathrm{v})$, and assayed for fluorescence content. The concentration of each metabolite was calculated from its relative concentration on the TLC plate and the total fluorescence and corrected for nonspecific fluorescence, as determined from samples obtained prior to therapy with MCM.

Urine analyses. Samples $(5 \mathrm{ml})$ of urine were each extracted with $1 \mathrm{ml}$ chloroform/isopropanol, $1: 1(\mathrm{v} / \mathrm{v})$. The organic phase was separated by centrifugation at $27,000 \mathrm{~g}$ for $15 \mathrm{~min}$ at $4^{\circ} \mathrm{C}$, and collected. Aliquots $(50 \mu \mathrm{l})$ were added to $2 \mathrm{ml}$ isopropanol/2.16 $\mathrm{N}$ sulfuric acid, $75: 25(\mathrm{v} / \mathrm{v})$, and the total fluorescence was measured. Values were corrected for the nonspecific fluorescence as determined from urines sampled prior to drug administration. For the quantification of parent compound and metabolites, another $50-\mu \mathrm{l}$ aliquot of the organic phase was spotted on a TLC plate that was processed in the same way as for plasma.

HPLC analyses. HPLC analyses were done according to a modification of the method described by Andrews et al. [1] on a Spectra Physics 3500 B HPLC (Santa Clara, Calif) fitted with a $\mu$-Bondapak Phenyl column $(3.9 \mathrm{~mm} \times 30 \mathrm{~cm}$, Waters Associates, Milford, Mass). The column was eluted with a 10 -min gradient of $32 \%-72 \%$ of tetrahydrofuran in a $0.1 \%$ (w/v) ammonium formate buffer $(\mathrm{pH} 4.0)$ at a flow rate of $2 \mathrm{ml} / \mathrm{min}$. Fluorescent compounds were detected with an Aminco fluoromonitor fitted with a $470-\mathrm{nm}$ excitation filter and a 500-nm cutoff emission filter.

For the analysis of plasma or urines, the organic phase resulting from the chloroform/isopropanol extraction was resuspended in tetrahydrofuran and injected onto the HPLC.

Mass spectral analyses. Mass spectral analyses were done on a VG Micromass 30F mass spectrometer (VG Analytical, Altrhincham, England) operated under VG Data Systems 2040 computer control. Spectra were obtained every $7 \mathrm{~s}$ over the range of 600-20 atomic mass units at a scan rate of $10 \mathrm{~s} /$ decade. Source conditions were $200^{\circ} \mathrm{C}, 70$ electron-volt ionizing voltage, $170 \mu \mathrm{Amp}$ trap current, and $4 \mathrm{kV}$ accelerating voltage.

Identification of metabolites structure. Metabolites were identified by co-chromatography on TLC and HPLC with known 
standards. Musettamycin, pyrromycin, and pyrromycinone were supplied by Bristol-Myers Laboratories, Syracuse, NY. Other metabolites were identified by TLC, HPLC, and mass spectral analyses.

In vitro studies. Selected metabolites were submitted to enzymatic hydrolysis by $\beta$-glucuronidase and arylsulfatase. Hydrolysis by $\beta$-glucuronidase was carried out at $37^{\circ} \mathrm{C}$ in $0.1 \mathrm{M}$ phosphate buffer ( $\mathrm{pH} 7.4$ ) for $18 \mathrm{~h}$. Hydrolysis by arylsulfatase was performed at $37^{\circ} \mathrm{C}$ for $18 \mathrm{~h}$ in $0.1 \mathrm{M}$ acetate buffer $(\mathrm{pH}$ 4.6). Phenolphthtalein glucuronic acid and $p$-nitrocatechol sulfate were used to check the activity of $\beta$-glucuronidase and arylsulfatase, respectively. The specificity of each enzyme was demonstrated by the absence of activity of $\beta$-glucuronidase on $p$-nitrocatechol sulfate and of arylsulfatase on phenolphthalein glucuronic acid. Partial hydrolysis of MCM to musettamycin and $\mathrm{M} 2$ was obtained by incubation with $0.1 \mathrm{~N} \mathrm{HCl}$ for $4 \mathrm{~h}$ at room temperature. Hydrolysis to pyrromycinone was obtained by incubation for $30 \mathrm{~min}$ at $100^{\circ} \mathrm{C}$ with $0.1 \mathrm{~N} \mathrm{HCL}$. Finally, MCM was converted to 7-deoxypyrromycinone, bisanhydropyrromycinone, and a third, less abundant, aglycone by incubation at $37^{\circ} \mathrm{C}$ under anaerobic conditions in the presence of purified NADPH-cytochrome $\mathrm{P} 450$ reductase, 40 $\mathrm{m} M$ phosphate buffer ( $\mathrm{pH} 7.4$ ), and an NADPH generating system [5].

Pharmacokinetic simulation. Pharmacokinetic analyses were performed on the Adapt program (University of Maryland Computer Center, University of Maryland, Baltimore, Md). Half-lives, areas under the curve, and clearances were calculated according to Gibaldi et al. [12].

Statistical comparisons. A Student's $t$-test was used for statistical comparisons.

\section{Results}

\section{Identification of metabolites}

In addition to MCM, five other fluorescent compounds were consistently observed in plasma and urines. Their mobility in TLC and the retention time of each in HPLC are listed in Table 1, and the proposed structures of some of these metabolites are shown in Fig. 2. M2 was a contaminant present

Table 1. Chromatographic properties of marcellomycin and related metabolites

\begin{tabular}{llll}
\hline & $\begin{array}{l}\mathrm{R}_{\mathbf{f}} \text { in TLC } \\
\text { System I }\end{array}$ & $\begin{array}{l}\mathrm{R}_{\mathrm{f}} \text { in TLC } \\
\text { System II }\end{array}$ & $\begin{array}{l}\text { Retention } \\
\text { time in } \\
\text { HPLC (s) }\end{array}$ \\
\hline G1 & 0.94 & 0.74 & 560 \\
Bisanhydro- & 0.94 & 0.74 & 560 \\
pyrromycinone & & & \\
7-Deoxypyrromycinone & 0.90 & 0.49 & 602 \\
Pyrromycinone & 0.88 & 0.40 & 390 \\
G2 & 0.77 & 0.21 & ND \\
Pyrromycin & 0.70 & 0 & 305 \\
Musettamycin & 0.58 & 0 & 256 \\
Marcellomycin & 0.54 & 0 & 256 \\
M2 & 0.48 & 0 & 223 \\
P1 & 0.36 & 0 & 256 \\
P2 & 0.33 & 0 & 223 \\
\hline
\end{tabular}

a ND, not done in the parent drug. Following mild acid hydrolysis, MCM was converted to musettamycin and pyrromycin, whereas M2 was converted to a mixture of pyrromycin and another fluorescent compound, slightly more polar than musettamycin. Following acid hydrolysis at $100^{\circ} \mathrm{C}$, both $\mathrm{MCM}$ and M2 were converted to pyrromycinone. $\mathrm{P} 1$ and $\mathrm{P} 2$ were acid-hydrolyzed to $\mathrm{MCM}$ and $\mathrm{M} 2$, respectively, and therefore represented conjugates. However, they resisted hydrolysis by arylsulfatase and $\beta$-glucuronidase. $\mathrm{G} 1$ and $\mathrm{G} 2$ resisted acid hydrolysis at $100^{\circ} \mathrm{C}$ and therefore represented aglycones. G1 had the same TLC and HPLC characteristics as bisanhydropyrromycinone.

\section{Plasma}

Plasma drug-related total fluorescence declined in a first-order fashion, with no fluorescence detectable by $48 \mathrm{~h}$ after the end of the infusion (Fig. 3). At the dosage of $40-50 \mathrm{mg} / \mathrm{m}^{2}$, the plasma concentration of MCM was well expressed by a triexponential equation (Fig. 4). At $27.5 \mathrm{mg} / \mathrm{m}^{2}$, less extensive computer simulation was possible because of the lack of data during the infusion and the early times after the end of the infusion. The elimination half-lives were $19.1 \pm 31.5$ (mean \pm SD) $\mathrm{h}$ and $41.9 \pm 19.2 \mathrm{~h}$ at $40-50$ and $27.5 \mathrm{mg} / \mathrm{m}^{2}$, respectively (Table 2). The apparant volume of the central compartment was $3.6 \pm 3.9$ and $7.1 \pm 2.41 / \mathrm{m}^{2}$ at the two dose levels, respectively. The systemic clearances were $1.50 \pm 0.88$ and
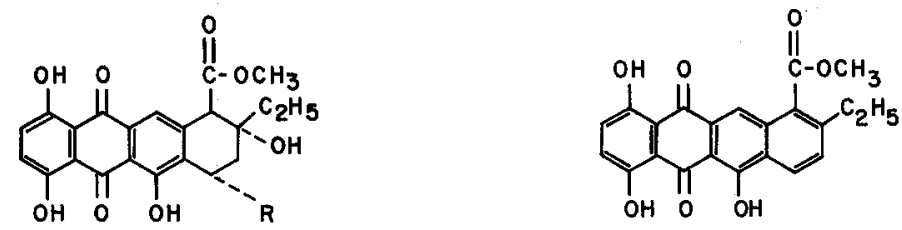

Bis anhydropyrromycinone

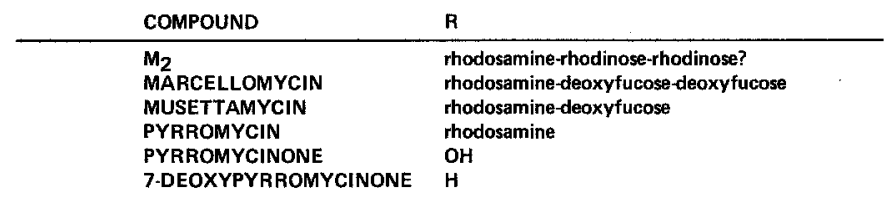

Fig. 2. Proposed structure for some of the metabolites of marcellomycin

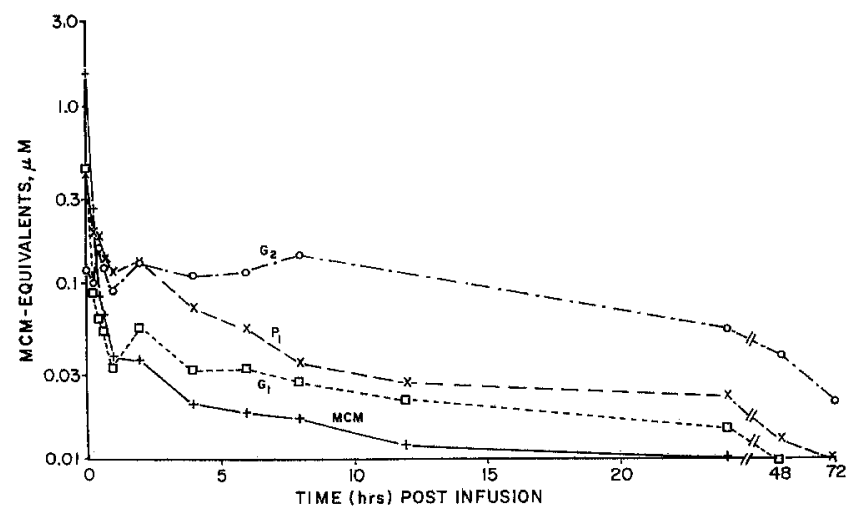

Fig. 3. Plasma concentration of total fluorescence in six patients treated with marcellomycin at a dosage of $40-50 \mathrm{mg} / \mathrm{m}^{2}$. Each point represents the mean of the six patients. Bars represent the standard deviation 
Table 2. Plasma pharmacokinetic parameters of MCM

\begin{tabular}{llllllll}
\hline $\begin{array}{l}\text { Dose } \\
\left(\mathrm{mg} / \mathrm{m}^{2}\right)\end{array}$ & $\begin{array}{l}\text { Number } \\
\text { of } \\
\text { patients }\end{array}$ & $\begin{array}{l}\text { Peak } \\
(\mu M)\end{array}$ & $\begin{array}{l}\text { Time of } \\
\text { peak } \\
(\mathrm{min})\end{array}$ & $\begin{array}{l}\text { Terminal } \\
\text { half-life } \\
(\mathrm{h})\end{array}$ & $\begin{array}{l}\text { AUC } \\
(\mu M \times \mathrm{h})\end{array}$ & $\begin{array}{l}\text { Clearance } \\
\left(\mathrm{l} / \mathrm{min} / \mathrm{m}^{2}\right)\end{array}$ & $\begin{array}{l}\text { Apparent volume } \\
\text { of central } \\
\text { compartment } \\
\left(1 / \mathrm{m}^{2}\right)\end{array}$ \\
\hline 27.5 & 3 & $0.02 \pm 0.02^{\mathrm{b}}$ & $\overline{-}^{\mathrm{c}}$ & $41.9 \pm 19.2$ & $0.36 \pm 0.07$ & $0.91 \pm 0.02$ & $7.1 \pm 2.4$ \\
$40-50$ & 6 & $1.67 \pm 0.61$ & 0 & $19.1 \pm 31.5$ & $0.82 \pm 0.45$ & $1.50 \pm 0.88$ & $3.6 \pm 3.9$ \\
\hline
\end{tabular}

a The AUC (area under the plasma concentration-time curve) was calculated from the end of the infusion to infinity

b Mean \pm SD

c Not evaluable because of the absence of early time points. The indicated peaks were observed 30 min after the end of the infusion

Table 3. Plasma pharmacokinetic parameters of marcellomycin metabolites

\begin{tabular}{lllllll}
\hline Metabolite & $\begin{array}{l}\text { Number } \\
\text { of } \\
\text { patients }\end{array}$ & $\begin{array}{l}\text { Dose of } \\
\text { MCM } \\
\left(\mathrm{mg} / \mathrm{m}^{2}\right)\end{array}$ & $\begin{array}{l}\text { Peak } \\
(\mu M)\end{array}$ & $\begin{array}{l}\text { Time of } \\
\text { peak } \\
(\mathrm{min})\end{array}$ & $\begin{array}{l}\text { Elimination } \\
\text { rate } \\
\left(\mathrm{h}^{-1}\right)\end{array}$ & $\begin{array}{l}\mathrm{AUC}^{\mathrm{a}} \\
(\mu M \times \mathrm{h})\end{array}$ \\
\hline P1 & 3 & 27.5 & $0.08 \pm 0.03^{\mathrm{b}}$ & $-^{\mathrm{c}}$ & $0.18 \pm 0.16$ & $0.52 \pm 0.25$ \\
P1 & 6 & $40-50$ & $0.43 \pm 0.16$ & 0 & $0.17 \pm 0.06$ & $1.37 \pm 1.04$ \\
$\mathrm{G} 1$ & 3 & 27.5 & $0.05 \pm 0.03$ & $-^{\mathrm{c}}$ & $0.14 \pm 0.14$ & $0.55 \pm 0.26$ \\
$\mathrm{G} 1$ & 6 & $40-50$ & $0.46 \pm 0.30$ & 0 & $0.11 \pm 0.04$ & $1.06 \pm 0.76$ \\
$\mathrm{G} 2$ & 3 & 27.5 & $0.01 \pm 0.01$ & $-^{\mathrm{c}}$ & $0.68 \pm 0.94$ & $0.10 \pm 0.09$ \\
$\mathrm{G} 2$ & 6 & $40-50$ & $0.20 \pm 0.13$ & 30 & $0.07 \pm 0.04$ & $3.91 \pm 2.90$ \\
\hline
\end{tabular}

a The AUC (area under the plasma concentration-time curve) was calculated from the end of the infusion to infinity

b Mean $\pm \mathrm{SD}$

c Not evaluable because of the lack of early time points. The indicated peaks correspond to the concentrations at $30 \mathrm{~min}$

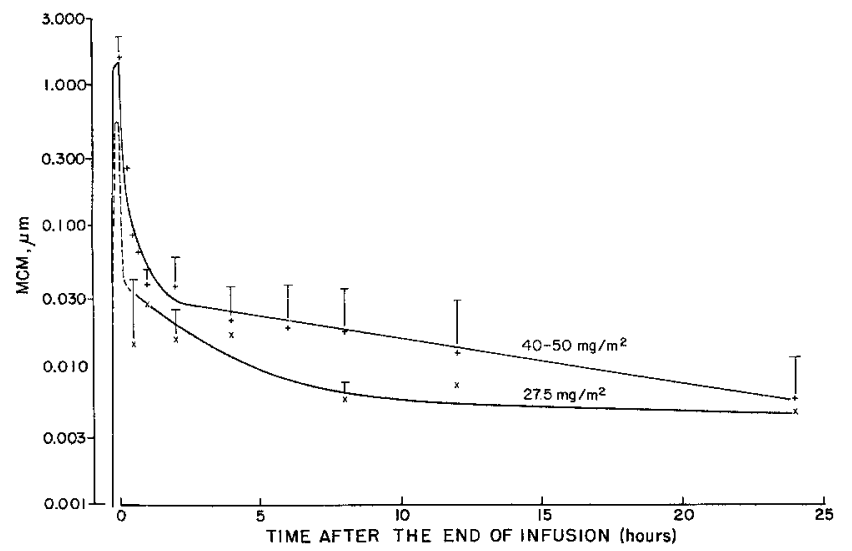

Fig. 4. Plasma concentration of parent drug in patients treated with marcellomycin at a dosage of $27.5 \mathrm{mg} / \mathrm{m}^{2}$ (3 patients) or $40-50 \mathrm{mg} / \mathrm{m}^{2}$ (6 patients). Each point represents the mean of three or six values. Standard deviation bars have been omitted for clarity. The curves are obtained by computer simulation

$0.90 \pm 0.021 / \mathrm{min} / \mathrm{m}^{2}$ at $40-50$ and $27.5 \mathrm{mg} / \mathrm{m}^{2}$, respectively The pharmacokinetic parameters do not differ between the two dose levels. The area under the plasma concentration-time plot (AUC) from the end of the infusion to infinity was $0.82 \pm$ 0.45 and $0.36 \pm 0.07 \mu M \times$ h at $40-50$ and $27.5 \mathrm{mg} / \mathrm{m}^{2}$, respectively. At $40-50 \mathrm{mg} / \mathrm{m}^{2}$, sufficient data were available to calculate the AUC during the infusion time. The value was $0.26 \pm 0.08 \mu M \times \mathrm{h}$.

At $40-50 \mathrm{mg} / \mathrm{m}^{2}$, peak plasma concentrations were $0.43 \pm$ $0.16,0.46 \pm 0.30$, and $0.20 \pm 0.13 \mu M$ for P1, G1, and G2,

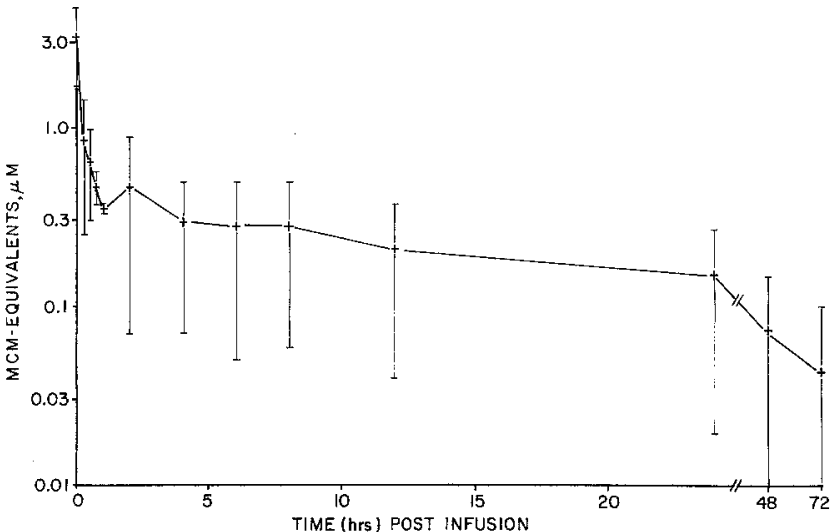

Fig. 5. Plasma concentrations of parent drug and metabolites in six patients treated with marcellomycin at a dosage of $40-50 \mathrm{mg} / \mathrm{m}^{2}$. Each point represents the mean of six observations. Standard deviation bars have been omitted for clarity

respectively (Fig. 5). The peak concentrations of P1 and G1 were observed at the end of the infusion, whereas that of G2 was seen at $30 \mathrm{~min}$ after the end of the infusion. The elimination rates were $0.17 \pm 0.06 \mathrm{~h}^{-1}$ for $\mathrm{P} 1$ and $0.11 \pm$ $0.04 \mathrm{~h}^{-1}$ for $\mathrm{G} 1$. The concentrations of $\mathrm{G} 2$ appeared to be stable up to $8 \mathrm{~h}$. Thereafter, $\mathrm{G} 2$ declined progressively, with an elimination rate of $0.07 \pm 0.04 \mathrm{~h}^{-1}$. The AUCs were $1.37 \pm$ $1.04,1.06 \pm 0.76$, and $3.91 \pm 2.90 \mu M \times \mathrm{h}$ for $\mathrm{P} 1, \mathrm{G} 1$, and $\mathrm{G} 2$, respectively. The peak concentrations, the elimination rates, and AUCs for these compounds at $27.5 \mathrm{mg} / \mathrm{m}^{2}$ are listed in 
Table 4. Urinary pharmacokinetic data

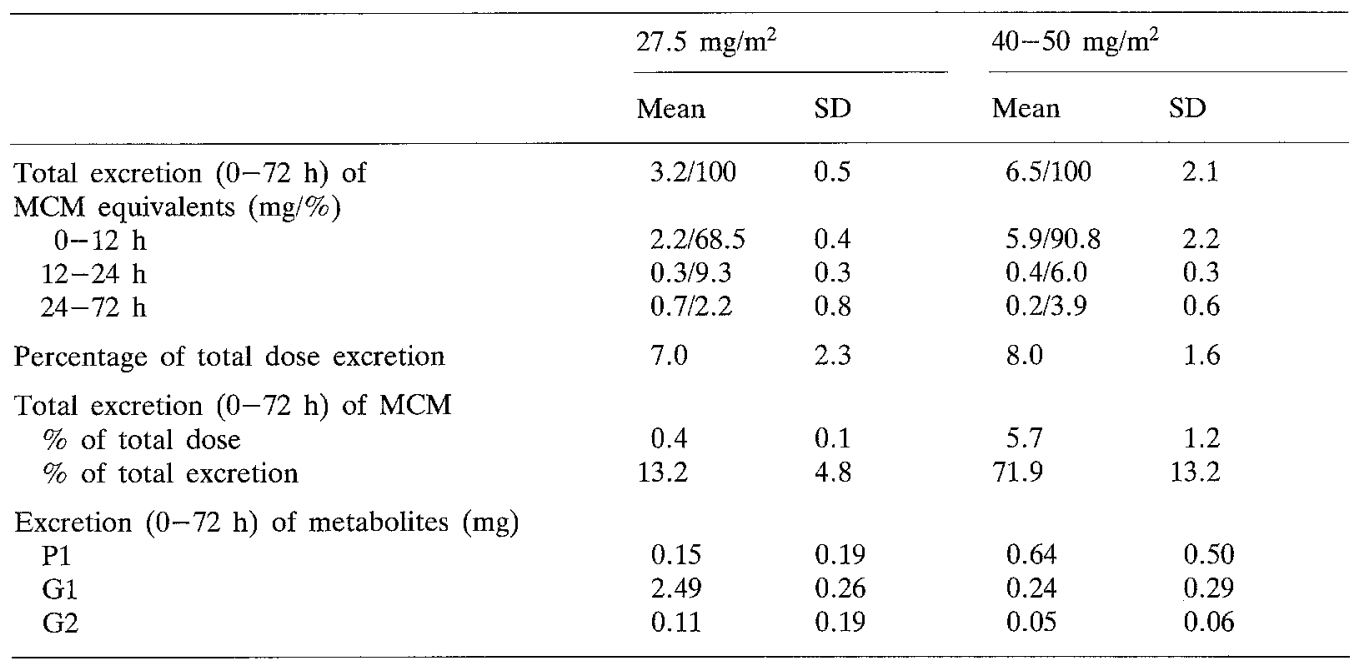

Table 5. Correlation between pharmacokinetic parameters and clinical data

\begin{tabular}{|c|c|c|c|c|c|c|c|c|c|c|c|c|c|c|c|}
\hline \multirow[t]{3}{*}{ Patient } & \multicolumn{2}{|c|}{ Pretreatment } & \multirow{3}{*}{$\begin{array}{l}\text { Dose } \\
\left(\mathrm{mg} / \mathrm{m}^{2}\right)\end{array}$} & \multirow{3}{*}{ 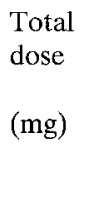 } & \multirow{3}{*}{$\begin{array}{l}\begin{array}{l}\text { Nadir }^{2} \\
\text { WBC }\end{array} \\
\left(\times 10^{3} / \mathrm{m}\right.\end{array}$} & \multirow{3}{*}{$\frac{\begin{array}{l}\text { Nadir } \\
\text { platelets }\end{array}}{\left.\mathrm{nm}^{3}\right)}$} & \multicolumn{4}{|c|}{$\mathrm{AUC}^{\mathrm{b}}$} & \multicolumn{4}{|c|}{ Peak concentration } & \multirow{3}{*}{$\begin{array}{l}\text { Total body } \\
\text { clearance } \\
\text { parent } \\
\text { drug } \\
\left(1 / \mathrm{min} / \mathrm{m}^{2}\right)\end{array}$} \\
\hline & \multirow{2}{*}{$\begin{array}{l}\text { Serum } \\
\text { creatinine } \\
(\mathrm{mg} \%)\end{array}$} & \multirow{2}{*}{$\begin{array}{l}\text { Serum } \\
\text { bilirubin } \\
(\mathrm{mg} \%)\end{array}$} & & & & & $\mathrm{MCM}$ & $\mathrm{P} 1$ & $\mathrm{G} 1$ & $\mathrm{G} 2$ & $\mathrm{MCM}$ & $\mathrm{P} 1$ & $\mathrm{G} 1$ & $\mathrm{G} 2$ & \\
\hline & & & & & & & $(\mu M)$ & h) & & & $(\mu M)$ & & & & \\
\hline 1 & 0.9 & 0.5 & 50 & 76 & 0.9 & 35 & 0.9 & 2.9 & 0.9 & 5.8 & 1.1 & 0.5 & 0.3 & 0.2 & 1.2 \\
\hline 4 & 0.7 & 0.3 & 50 & 71 & 2.0 & 95 & 0.6 & 0.8 & 2.2 & 2.2 & 1.3 & 0.3 & 0.4 & 0.1 & 2.9 \\
\hline 5 & 1.4 & 0.4 & 40 & 73 & 3.3 & 177 & 1.2 & 0.8 & 1.3 & 4.9 & 2.0 & 0.4 & 0.5 & 0.1 & 0.9 \\
\hline 6 & 1.2 & 0.2 & 40 & 72 & 5.4 & 178 & 1.3 & 0.5 & 0.5 & 0.9 & 1.1 & 0.2 & 0.2 & 0.1 & 0.6 \\
\hline
\end{tabular}

a WBC, white blood cells

b The AUC (area under the plasma concentration-time curve) was calculated from the start of the infusion to infinity

Table 3. The elimination rate for $\mathrm{G} 2$ appears to be slower with $40-50 \mathrm{mg} / \mathrm{m}^{2}$ but, because of the wide interpatient variations, the difference is not significant. There is no indication that the pharmacokinetics of these metabolites is different at the two dose levels.

\section{Urines}

The total urinary excretion of fluorescent compounds from the start of the infusion until $72 \mathrm{~h}$ after treatment was $6.5 \pm 2.1 \mathrm{mg}$ MCM equivalents at $40-50 \mathrm{mg} / \mathrm{m}^{2}$ and $3.2 \pm 0.5 \mathrm{mg} \mathrm{MCM}$ equivalents at $27.5 \mathrm{mg} / \mathrm{m}^{2}$. These values represented $8.1 \% \pm$ $1.6 \%$ and $7.0 \% \pm 2.3 \%$ of the total administered dose, respectively $(P=\mathrm{NS})$. The excretion of fluorescent compounds occurred mainly during the first hours after treatment. By $12 \mathrm{~h}, 68 \%$ of the fluorescent compounds had been excreted. At $40-50 \mathrm{mg} / \mathrm{m}^{2}$, MCM was the predominant compound $(71.9 \% \pm 13.3 \%$ of the total urinary anthracyclines). P1, G1, and $\mathrm{G} 2$ represented $9.8 \%, 3.7 \%$, and $0.8 \%$ of the total urinary anthracyclines, respectively. In contrast, at $27.5 \mathrm{mg} / \mathrm{m}^{2}, \mathrm{G} 1$ was the dominant compound $(77.8 \% \pm 5.1 \%$ of the total urinary anthracyclines); MCM represented only $13.2 \%, \mathrm{P} 1$, $4.7 \%$, and $\mathrm{G} 2,3.4 \%$. The excreted proportion of MCM was significantly lower at $27.5 \mathrm{mg} / \mathrm{m}^{2}(P \leq 0.001)$. G1 was identified by cochromatography as bisanhydropyrromycinone. The most important urinary data are listed in Table 4.

\section{Correlation between pharmacokinetic parameters and clinical data}

This correlation was studied for the six patients treated at the dosage of $40-50 \mathrm{mg} / \mathrm{m}^{2}$ every 3 weeks. The other patients were treated weekly; wherein, toxicity is not related only to the first course, when the pharmacologic evaluation was done. Myelosuppression was the major toxicity encountered in these patients. The correlations between leukopenia and thrombocytopenia and the peak plasma concentrations and AUCs for MCM and the different metabolites are presented in Table 5. No clear correlation emerges from these data. Nor was any correlation found between myelosuppression and other pharmacokinetic parameters. Other side-effects were much less frequent and no correlation with the pharmacokinetic parameters was attempted.

\section{Discussion}

Marcellomycin (MCM) is a new class II anthracycline antitumor antibiotic that was introduced into clinical trials 
mainly because of its lack of myelosuppression in the animal models used in the preclinical evaluation of this drug [4, 18]. Unfortunately, hopes were disappointed, in that myelosuppression was the major dose-limiting toxicity in the two clinical trials conducted with this drug $[13,15]$. In addition, myelosuppression was erratic and unpredictable.

In plasma, total drug-derived fluorescence declined progressively according to first-order kinetics. This decrease is radically different from that observed with aclacinomycin $A$ (ACL), the only other class II anthracycline studied $[9,10]$. With the latter compound, after a rapid decrease of total fluorescence a rebound occurs, with plasma concentrations of total fluorescence reaching values higher than those just after the injection [9]. A similar difference in plasma pharmacokinetics has also been found between ACL and MCM in mice [7]. These findings emphasize that even minor differences in the anthracycline structure can lead to profound pharmacologic differences.

In plasma, in addition to MCM, five fluorescent compounds were observed. Two of these were related to a contaminant in the parent drug. It is noteworthy that the proportion of the contaminants was found to be stable from one batch of drug to another, and no correlation was detected between the pharmacokinetic parameters of these compounds and the clinical toxicities encountered in the patients. These points render a role of the contaminants in the erratic toxicity observed during the clinical trials unlikely.

One metabolite (P1) was hydrolyzed by mild acid hydrolysis to $\mathrm{MCM}$, indicating that $\mathrm{P} 1$ was a conjugate of MCM. However, P1 resisted hydrolysis by $\beta$-glucuronidase and arylsulfatase. We cannot exclude a conjugation at another site of the molecule on the basis of our data. Two aglycones $(\mathrm{G} 1, \mathrm{G} 2)$ were seen in the plasma. By co-chromatography on TLC and HPLC, G1 was identified as bisanhydropyrromycinone. This aglycone can be produced in vitro by incubating MCM with rat liver preparation or purified NADPH-cytochrome $\mathrm{P} 450$ reductase [5]. The hepatic metabolism of MCM could therefore account for the presence of this aglycone; however, since it was also present in small amounts in the parent drug, a contamination cannot be excluded. G2 did not correspond to any of the standards that we were using, and its structure remains unidentified. Because of the similarities between MCM and ACL, the metabolic pathways observed for ACL could give some information about the possible pathways for MCM. In the case of ACL, in addition to 7-deoxyaglycones, dimer of the 7-deoxyaglycones, and conjugates, a compound lacking the ester goup in $\mathrm{C} 10$ has been identified [10]. Unfortunately, insufficient amounts of G2 precluded further identification.

At $40-50 \mathrm{mg} / \mathrm{m}^{2}$, peak plasma concentrations of metabolites were lower than that of MCM. Slow elimination of these metabolites resulted in AUCs similar (G1) or higher (P1, G2) than that of MCM. At $27.5 \mathrm{mg} / \mathrm{m}^{2}$, no data were available during the first $30 \mathrm{~min}$ after the infusion, so that peak concentrations were not available. The AUCs for the metabolites are again in the same range as for the parent drug. The body exposure to these metabolites was therefore significant and must be taken into account to explain the therapeutic activity and the toxicity of the drug. In the case of other anthracyclines, aglycones are considered as inactive antitumor compounds $[8,17]$, but the glycosidic metabolites retain the activity of the parent drug partially or totally [2, 17, 21]. No data are available on the antitumor efficacy and toxicity of the various metabolites of MCM. Recently, Fourcade et al. [11] demonstrated that ACL and ACL-derived glycosides are active against Friend leukemic cells, whereas aglycones are not. It is likely that, similarly, MCM-derived aglycones are inactive, in contrast to $\mathrm{MCM}$ and its conjugates.

Nonlinear pharmacokinetic behavior can occur whenever any physiologic pathway is saturated. Robert et al. have reported nonlinear pharmacokinetic behavior for Adriamycin (ADM) [19], but this phenomenon was described only during the distribution phase. In the case of MCM, our limited data do not support any difference between the dosages of 27.5 and $40-50 \mathrm{mg} / \mathrm{m}^{2}$. In fact, the interpatient differences were much wider than the differences between the two dosages.

The urinary excretion of MCM amounted to less than $10 \%$ of the total administered dose. This low recovery does not appear to be related to the fact that the urines were collected only during the first $72 \mathrm{~h}$ after treatment. Indeed, the maximum excretion occurred during the first $12 \mathrm{~h}$ after infusion and decreased sharply thereafter. Therefore, it can be concluded that MCM is excreted primarily by nonrenal routes. By analogy with other anthracycline antibiotics, the bile is likely to be the major excretory route for MCM. In urines, the relative excretion of parent drug and various metabolites was different at 27.5 than at $40-50 \mathrm{mg} / \mathrm{m}^{2}$. MCM was predominant at the higher dosage, whereas bisanhydropyrromycinone was the major urinary compound at the lower dosage. No obvious explanation is emerge to justify this difference. The urinary metabolites were the same as those encountered in plasma.

One of the major goals of this study was to explain the differences in toxicity encountered among the patients, and between humans and animal models. The data presented in this study do not suggest any correlation between myelosuppression and the various pharmacokinetic parameters. This might be related to the small number of patients, but also to the interaction of other factors, like local distribution, local uptake, target cell sensitivity, and others. In comparison to mice, we did not find any qualitative differences between the human and murine pharmacokinetics of MCM [7]. The same metabolites were identified. However, important quantitative differences do exist. Mice have higher AUC for parent drug, but lower AUC for the metabolite P1. The relevance of these observations to the difference in toxicity between mouse and man remains to be established.

\section{References}

1. Andrews PA, Brenner DE, Chou FE, Kubo H, Bachur NR (1980) Facile and definitive determination of human adriamycin and daunorubicin metabolites by high-pressure liquid chromatography. Drug Metab Dispos 8:152

2. Benjamin RS (1981) Clinical pharmacology of daunorubicin. Cancer Treat Rep [Suppl 4] 65:109

3. Benjamin RS, Riggs CE, Bachur NR (1977) Plasma pharmacokinetics of adriamycin and its metabolites in humans with normal hepatic and renal function. Cancer Res 37:1416

4. Bradner WT, Huftalen JB (1978) Marcellomycin: an anthracycline without leukopenic effect in $\mathrm{BDF}_{1}$ mice. Proc Am Assoc Cancer Res 19: 46

5. Chang B, Dodion P, Tamburini JM, Riggs CE, Bachur NR (1983) In vitro metabolism of marcellomycin. Proc Am Assoc Cancer Res $24: 258$

6. Crooke ST, Duvernay VH, Galvan L, Prestayko AW (1978) Structure-activity relationships of anthracyclines relative to effect on macromolecular syntheses. Mol Pharmacol 14:290 
7. Dodion P, Egorin MJ, Tamburini JM, Riggs CE, Bachur NR (1983) The murine metabolism and disposition of marcellomycin. Proc Am Assoc Cancer Res 24: 254

8. Driscoll JS, Hazard GF, Wood HB, Goldin A (1974) Structure-antitumor activity relationships among quinone derivatives. Cancer Chemother Rep 4:1

9. Egorin MJ, Van Echo D, Fox BM, Whitacre M, Bachur NR (1982) Plasma kinetics of aclacinomycin $\mathrm{A}$ and its major metabolites in man. Cancer Chemother Pharmacol 8:41

10. Egorin MJ, Andrews PA, Nakazawa H, Bachur NR (1983) Purification and characterization of aclacinomycin $A$ and its metabolites from human urine. Drug Metab Dispos 11:167

11. Fourcade A, Farhi JJ, Bennoun M, Goldschmidt E, Tapiero H (1983) Fate of aclacinomycin-A and its metabolites effect on cell growth and macromolecular synthesis. Biochem Pharmacol 32: 1819

12. Gibaldi M, Perrier D (1982) Multicompartment models. In: Pharmacokinetics. Dekker, New York, p 45

13. Joss RA, Kaplan S, Goldhursh A, Varini M, Brunner KW, Cavalli F (1983) A phase I trial of marcellomycin with a weekly dose schedule. Eur J Cancer Clin Oncol 19:455

14. Nettleton DE, Bradner WT, Bush JA, Coon AB, Moseley JE, Myllymaki RW, O'Herron FA, Schreiber RH, Vulcano AL (1977) New antitumor antibiotics: musettamycin and marcellomycin from bohemic acid complex. J Antibiot (Tokyo) 30:525

15. Nicaise C, Rozencweig M, DeMarneffe M, Crespeigne N, Dodion P, Piccart M, Sculier JP, Lenaz L, Kenis Y (1983) Clinical phase I trial with marcellomycin with a single-dose schedule. Eur J Cancer Clin Oncol 19: 449

16. Oki T, Takeuchi T, Oka S, Umezawa H (1980) New anthracycline antibiotic aclacinomycin A: experimental studies and correlations with clinical trials. Recent Res Cancer Res 76:22

17. Ozols RF, Willson JKV, Weltz MD, Grotzinger KR, Myers CE, Young RC (1980) Inhibition of human ovarian cancer colony formation by adriamycin and its major metabolites. Cancer Res 40: 4109

18. Reich SD, Bradner WT, Rose WC, Schurig JE, Madissoo H, Johnson DF, DuVernay VH, Crooke ST (1980) Marcellomycin. In: ST Crooke, SD Reich (eds) Anthracyclines: Current status and new development. Academic Press, New York, p 343

19. Robert J, Hoerni B, Vrigaud P, Lagarde C (1983) Early phase pharmacokinetics of doxorubicin in non-Hodgkin lymphoma patients. Cancer Chemother Pharmacol 10:115

20. Rozencweig $M$, Nicaise $C$, Dodion $P$, Piccart $M$, Bron $D$, Mattelaer M, Dumont G, Atassi G, Strijkmans P, Kenis Y (1981) Marcellomycin: preclinical and clinical aspects. In: FW Muggia, CW Young, SK Carter (eds) Anthracycline antibiotics in cancer therapy. Nijhoff, The Hague, p 549

21. Young RC, Ozols RF, Myers CE (1981) The anthracycline antineoplastic drugs. N Engl J Med 305: 139

Received November 14, 1983/Accepted May 10, 1984 